\title{
Editorial
}

\section{Nation brand as context and reputation}

As I noted in my editorial in the second issue of Place Branding, there is a great deal of confusion about what branding really is: perhaps the most common mistake is to consider branding as a species of message. I have always found it useful to think of brand as the context in which messages are received, rather than the message itself. Messages come under the category of marketing communications; brand, on the other hand, is the pre-existing background reputation, the perception of the subject matter of that message, and it fundamentally conditions the way in which any message is received and interpreted by the audience.

This is why a country with a poor brand often finds that the world's media will react with cynicism or indifference to its most enlightened actions and communications, while countries with strong brands seem to have little trouble gaining respect and attention for their most mediocre pronouncements.

America, a country currently perceived and portrayed by much of the world's media as a cynical and heartless bully, finds that its many humanitarian interventions are either under-reported or interpreted as cynical self-interest, while less substantial efforts from a 'popular' country like Sweden or Canada are praised to the skies. It would make a fascinating research project to analyse how the international media comments on the productions, pronouncements and policies of countries with weak brands compared to those with strong brands.

In an ideal world, countries would not and should not be branded like products, because they are too complex and too contradictory: they are sometimes good and sometimes bad, progressive in some areas and backward in others, tolerant in some ways and intolerant in others. The policies of their governments ought never to be conflated with the morals of their society, or the quality of their products with the culture of their citizens; yet this is what happens, and it is something which governments have no choice but to deal with as best they can.

The tendency to sum up countries and their governments in a simple and convenient formula is a habit of the marketplace, faithfully reflected in the media. In order to navigate through the complexities of modern society, people need shorthands for countries, and if countries do not do whatever is in their power to ensure that the shorthand is at least positive - it can never be complete or entirely fair — they may well end up with a damagingly negative one. In this respect, place branding can be described as a species of self-defence (which is often pre-emptive) against the tendency of the marketplace to vulgarise, to trivialise and to summarise in ways which are often unfair.

In consequence, nation branding, whether we like it or not, is a necessity; and countries which want to compete 
effectively in a globalised world must do battle with the constant urge of the marketplace to see the world in terms of simple national stereotypes. Countries must do whatever they can to upgrade and 'upbrand' those images, to ensure that they become and remain as fair, as true, as complete and as useful to their aims as the marketplace is prepared to accept. That is the nature of the contest.

\section{CHANGING THE BRAND}

The distinction between message and context points to the real reason why nation branding is such a painstaking and demanding process. It is easy enough for a country to 'do marketing' and change its messages, since the sender is in control of them, but it is extremely hard to 'do branding' and change the context in which those messages are received, since this is a process which occurs in a remote and secure location over which the country has little or no influence: the mind of the audience. As if this were not difficult enough, context is also a highly fragmented phenomenon: the audience does not have one mind, but a constantly fluctuating group consciousness which stems from millions of private individual beliefs, perceptions and prejudices which coincide at some points and diverge at others, in ways which are bafflingly complex.

Just like planets in other solar systems which can only be identified indirectly by the effect of their gravitational fields on the behaviour of known and observable stars, a brand can seldom be measured or observed directly, but observing audience reactions to a country's actions and behaviours can make that country's brand stand out quite clearly. Ask people what they think about Russia or Sweden, and they probably will not be able to tell you much; but show them a consumer product, a piece of legislation, a holiday destination, and compare their responses when told that it comes from Russia or from Sweden, and the dramatically different brands of those two countries will instantly emerge into the realm of perceivable, measurable phenomena.

Changing something this elusive is neither a simple nor a quick process, and it cannot be done without a very clear understanding of what the current brand is, a clear yet inspirational and widely shared vision of what the brand needs and deserves to become, and a psychologically viable process for leading the audience from the former to the latter. A strong brand strategy is essential for clarifying this process, keeping it on track and ensuring that every action and message of the country will assist the forward movement of the brand, rather than holding it back or moving it in the wrong direction.

Patience and unanimity of purpose are therefore fundamental to changing the brand of a country, but most countries face two obstacles to achieving these conditions: a lack of patience stemming from the four-year event horizon of most elected politicians (and a perfectly understandable desire to show measurable results within the electoral term); and the political difficulty of imposing a shared purpose on the stakeholders of the national brand, many of whom are commercial and political competitors, and over whom only the head of government or the head of state can exercise direct authority.

When the place being branded is a city or small country, this problem is more tractable (and differences among stakeholder interests also tend to diminish in proportion to the gravity of the country's image problems), but in larger, more prosperous countries, and especially in regions composed of several sovereign states, imposing a brand strategy is politically impossible.

In reality, imposing a brand strategy by 
authority, even where sufficient authority exists, is unlikely to be a very effective approach. One can compel people to do most things, but one cannot compel them to be enthusiastic; and an enthusiastic population or workforce is a prerequisite for building a powerful brand. This is perhaps part of the reason why the very clear and powerful nation brand strategies of some tyrants and dictators seldom achieve much impact beyond the borders of the state: the brand can only succeed by compulsion, and exerts little relevance or magnetism in the 'open marketplace'.

The kind of shared vision and common purpose which is a precondition of successful branding can only be achieved through 'soft power', and by a critical mass of stakeholders voluntarily endorsing and agreeing to support the national or regional brand strategy. This fact places enormous demands on the creative abilities of the team which devises the brand strategy (it must be clear, inspiring and motivating enough for competing stakeholders to forget their differences temporarily and agree to 'trade up' to it from their own convictions about what the strategy should be); on their salesmanship and rhetoric (it must be marketed internally); and on their willingness and ability to consult well and widely enough to build a sense of shared ownership of the idea without this hampering their ability to create something beyond mere political compromise. All too often in these cases, what starts out as a noble intention to come up with the idea that everyone loves ends up as a desperate struggle to come up with the idea that nobody minds.

Rather than a top-down authoritarian structure, the best model for implementing a nation brand is probably something closer to Al Qaeda than Josef Stalin: a loose network of semi-independent groups, each planning and carrying out its own activities and communications which are inspired by a commonly held belief in some simple, powerful mission. The reference to terrorist networks may be in dubious taste, but there is no denying the strength, resilience and effectiveness of such a model. 'Distributed leadership' is exactly what brands need in complex organisations like countries.

Perhaps a more wholesome image for the way in which a good nation brand strategy works is the magnet. Like magnets, powerful place brands have three key properties: they attract (consumers, tourists, talent, investors, respect, attention); they confer magnetism on to other objects (for example, a little of the magnetic appeal of Brand Italy rubs off on to Italian products and Italian people, and renders them equally attractive even when they are taken out of context); and they have the power to create order out of chaos (I am thinking of the school physics experiment where placing a magnet underneath a heap of iron filings on a sheet of paper causes the filings to arrange themselves into a symmetrical pattern). This final property is particularly relevant when we are discussing the administrative and organisational challenges in place branding: a powerful and attractive brand strategy can itself help to create spontaneous alignment of purpose and shared goals among normally competitive and even combative stakeholders.

\section{NATION BRAND AND THE STRUCTURES OF POWER}

The other problem — of political short-termism — is equally tricky to resolve. Countries with reigning monarchs have a distinct advantage here, in that royal families tend quite naturally 
to take a much longer view of the country's prospects than elected politicians. For a member of a royal family, the country is the "family business', and it may be relatively unimportant to any particular monarch whether progress in the brand image of his or her country takes place during his or her lifetime or in those of his or her descendants. This almost oriental view of time is precisely what place branding requires if it is to achieve its best and most durable effects.

In Britain and most other monarchies, we tend to consider our royal families as being merely one of a range of tourism 'products' which may or may not contribute to the country's heritage. This approach undeniably recognises some of the 'brand equity' inherent in royalty, but it may not be a sustainable practice in the longer term. It is a primary tenet of good brand strategy that one should contribute new equity to the brand as fast, or faster, than one exploits it. Just like sustainable forestry, good brand management recognises that the goodwill inherent in any brand is a commodity in finite supply, and must be stored up against future need. Simply exploiting the brand equity of the royal family as a tourist attraction is spending that equity without replenishing it.

If, on the other hand, one considers a royal family as naturally committed, long-term guardians of the national brand strategy (which, one could argue, is one of the things that the more enlightened royal families always have been, notwithstanding changes in the vocabulary used), an interesting role for royalty in the modern world begins to suggest itself.

Whatever structures one adopts for managing the nation brand, the translation from private to public sector practice will always be a political, intellectual and ethical challenge. The fact is that brand theory comes from commerce, and companies are very different organisations from countries; a contract of employment is a very different thing from a social contract; and the primary requirement of a company is to create profit, while the primary requirement of governance is to create viable communities.

In the commercial sector, it is openly acknowledged that a certain heavy handedness on the part of managers is usually required in order to achieve the kind of ruthless adherence to strategy and 'on-message behaviour' which companies need. There is, in fact, little that is democratic in the way that most companies are run, and powerful brands are often the result of a very single-minded, even mildly deranged, 'visionary' CEO who simply eliminates anybody who dares to deviate from the company line. To a degree this is comprehensible: so much of the success of any branding venture is attributable to the amount of consistency which the company manages to achieve in its internal and external communications that a somewhat despotic management style is often found to be the simplest way to achieve this. In a company it is also permissible to some degree, since one supposes that the employees are there of their own free will, and are being paid to perform in a way which the management decides is in the best interest of the company.

Countries, obviously, are different. A manager in a company may be ruthlessly single-minded and this can benefit the company enormously; the same approach by the leader of a country is called tyranny and seldom achieves positive results. Yet one knows from experience that getting many independent people and organisations, all with very different interests, opinions and agendas, to speak 
with a single voice is a hard thing to achieve through consensus.

One thing is clear: unless a government can find a way of achieving in its committees the same single-minded sense of purpose and control which the crazy brand visionary achieves within a privately owned company, nothing will come of the national brand programme and it is doomed to fail.

Looking for inspiration in the structures of terrorist networks, crazy corporate dictators and old-fashioned inherited monarchies may be a somewhat unconventional approach to devising national policy. But a little lateral thinking may be the very least that governments need to do in order to solve the riddles of implementing national brand strategy, that impossible necessity in today's branded world.

\section{Simon Anholt Managing Editor}

